\title{
Numerical Simulation Study of Field Scale SAGD and ES-SAGD Processes Investigating the Effect of Relative Permeabilities
}

\author{
Mohammad Ashrafi ${ }^{1}$, Yaser Souraki ${ }^{1} \&$ Ole Torsaeter $^{1}$ \\ 1 Department of Petroleum Engineering and Applied Geophysics, Norwegian University of Science and \\ Technology - NTNU, Trondheim, Norway \\ Correspondence: Mohammad Ashrafi, Department of Petroleum Engineering and Applied Geophysics, \\ Norwegian University of Science and Technology - NTNU, S.P.Andersens vei 15A, 7491 Trondheim, Norway. \\ Tel: 47-73-591-117. E-mail: mohammad.ashrafi@ntnu.no
}

\author{
Received: December 28, 2012 Accepted: February 5, 2013 Online Published: March 11, 2013 \\ doi:10.5539/eer.v3n1p93 \\ URL: http://dx.doi.org/10.5539/eer.v3n1p93
}

\begin{abstract}
Steam Assisted Gravity Drainage (SAGD) has been proved to be an effective method in producing from extra heavy oil or bitumen resources. The main recovery mechanism in this process is viscosity reduction by introducing heat into the reservoir. The Solvent Co-Injection processes (SCI) or Expanding Solvent SAGD (ES-SAGD) are alternative methods to the conventional SAGD. In these processes reduction in the oil viscosity is achieved by a combination of latent heat from steam and dissolution of solvents into bitumen. These alternative methods lower the steam requirements and associated costs with it, as well as the amount of carbon dioxide emission into the atmosphere caused by steam generation process.

In this work some numerical simulations were conducted to examine the effect of relative permeability data on the performance of SAGD and ES-SAGD processes. Temperature dependant relative permeability data, that shows variation of end points with temperature, was tested against fixed relative permeabilities. Oil production was found to be strongly dependant on the end point relative permeability data. It is suggested to use temperature dependant relative permeabilities in numerical simulations. This must be considered as a matching criterion, when trying to history match field data.

Solvent co-injection showed promising results both in terms of improved recovery factor and reduced steam oil ratio as an economical criterion. In addition, the high solvent recoveries of $97-100 \%$ in all solvent co-injection runs make the process even more economically interesting. Injecting only $2 \%$ on a molar basis of pentane, hexane or heptane as solvent, boosted the oil rates up.
\end{abstract}

Keywords: steam assisted gravity drainage, solvent co-injection, expanding solvent SAGD, bitumen, end point relative permeabilities

\section{Nomenclature}

CWE Cold Water Equivalents

ES-SAGD Expanding Solvent Steam Assisted Gravity Drainage

HSor High residual oil saturation relative permeability data set

K K-value

$k_{r} \quad$ Relative Permeability

LSor Low residual oil saturation relative permeability data set

$N \quad$ Oil or water Corey exponents in Corey relative permeability equation

$P \quad$ Absolute Pressure, $\mathrm{kPa} \quad \mathrm{S} \quad$ Fluid saturation

SAGD Steam Assisted Gravity Drainage SCI Solvent Co-Injection

SOR Steam to oil ratio $T$ Absolute Temperature, K

TD Temperature dependant relative permeability data set

VISC Fluid viscosity, cP 


\section{Subscripts}

o Oil

i Initial value

Superscript

O End point value $\begin{array}{ll}w & \text { Water } \\ r & \text { Residual value }\end{array}$

* $\quad$ Normalized value

\section{Introduction}

The idea of Steam Assisted Gravity Drainage (SAGD) process was introduced by Roger M. Butler in late 1970s as a thermal in-situ heavy oil recovery process. The procedure is applied to multiple well pairs. In this process, two horizontal wells separated by a vertical distance are placed near the bottom of the formation. The top horizontal well is used to inject steam, which rises forming a large steam chamber above the well, and the bottom well is used to collect the produced liquids (formation water, condensate, and oil). The rising steam condenses on the boundary of the chamber, heating and entraining the oil to the production well. The process leads to a high recovery and high oil rate at economic steam oil ratios (SOR) (Butler, 1981). This process, however, suffers from high energy requirements in order to produce steam. Access to water resources is crucial and generation of steam emits huge amount of carbon dioxide into the atmosphere. The energy requirement is expressed in terms of SOR, which is defined as the ratio of injected steam to the produced oil in this process.

In order to improve the energy efficiency of SAGD, some hybrid processes were introduced. These processes, usually known as Solvent Co-Injection (SCI) or Expanding Solvent Steam Assisted Gravity Drainage (ES-SAGD), are based on co-injection of limited amount of solvents together with steam (Nasr \& Isaac, 2001). These hydrocarbon solvents or solvent mixtures dissolve into the heated oil at the boundary of the steam chamber and will further reduce the bitumen viscosity.

Chow (1993) simulated the laboratory experiment of SAGD that was performed by Chung (1988). He was able to history match spreading steam chamber phase of his experiment using linear relative permeability curves, as the model had a very high absolute permeability. He mentioned, however, that the simulator was not able to fully match the rising steam chamber phase due to not having the capability of modeling oil and water emulsification that occurs as a result of counter current flow.

Kamath et al. (1999) modeled SAGD in two dimensions for heterogeneous layered oil sand reservoirs to study the effect of heterogeneity on the growth of steam chamber and the process performance. The effect of various reservoir parameters such as porosity, permeability, initial mobile water saturation, Dykstra-Parson's permeability variation, reservoir anisotropy and shale barriers on the SAGD process performance was investigated.

Later Kisman and Yeung (1995) performed a similar study with a two-dimensional numerical model which considers the relative effects of permeability, relative permeability, wettability changes, oil viscosity, thermal conductivity, flow barriers and solution gas.

Albahlani and Babadagli (2008) performed a critical review of the attempts in the literature to model the SAGD process and improve its performance. Their paper contains an intensive review highlighting the important parameters affecting the operation of SAGD. These parameters include porosity, thickness of the layer, gas saturation, permeability of the formation, viscosity and API of the bitumen, wettability of the rock and heterogeneity of the formation.

Deng et al. (2010) presented the results of a laboratory ES-SAGD process that uses diluents as the co-injected solvent to the steam. They highlight that use of a solvent mixture (such as diluents / naphtha) is superior to pure hydrocarbons due to its availability and reduced cost. They stated that the solubility of the solvent used in the ES-SAGD process needs to be determined in the bitumen sample experimentally, and the operating condition of the process must be tuned accordingly for a successful simulation of the experiments.

Yazdani et al. (2012) performed field scale simulation of the ES-SAGD process using normal alkanes $C_{3}$ to $C_{7}$ as solvents added to steam stream. According to them uncertainty in relative permeability data can have a significant effect on the performance of different solvents in the simulation study. It is recommended to use a solvent that follows the steam condensation behavior at the reservoir temperature and pressure condition (Yazdani et al., 2012). 


\section{Numerical Simulation Study}

In order to investigate the effect of temperature dependency of relative permeabilities on the field performance of SAGD and ES-SAGD, a numerical simulation study was conducted. Below is a summary of the model.

\subsection{3-D Numerical Model}

The model considered for this study was a 3-deminsional section of a reservoir. Due to symmetry of the SAGD process, only half of the area covered by the two wells is modeled. The section of the reservoir is $47 \mathrm{~m}$ in thickness, and the two horizontal wells are stretched all the way through $300 \mathrm{~m}$ length of the section in $\mathrm{y}$-direction. The spacing between horizontal well pairs is $100 \mathrm{~m}$. Therefore the width of the section considered is $50 \mathrm{~m}$. The grids are $25 \times 3 \times 26$ in $\mathrm{x}, \mathrm{y}$ and $\mathrm{z}$-directions respectively. The spacing between the horizontal injector and producer is $10 \mathrm{~m}$, and the producer is located $1.5 \mathrm{~m}$ above the formation base. Figure 1 illustrates the cross-sectional view of the model in two directions.

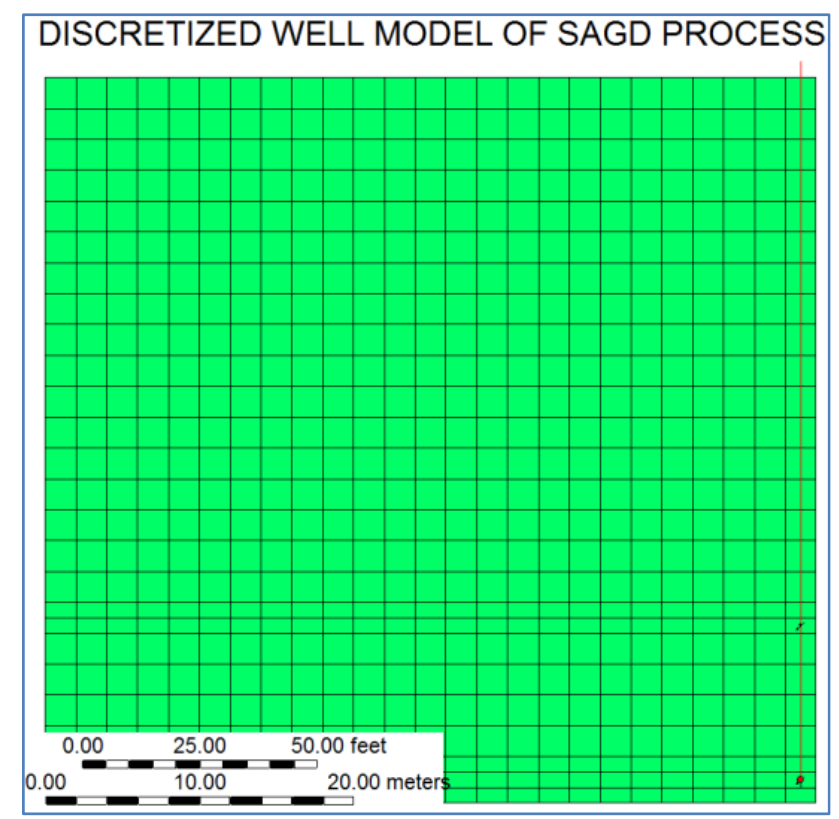

(a) I-K view of the simulation model

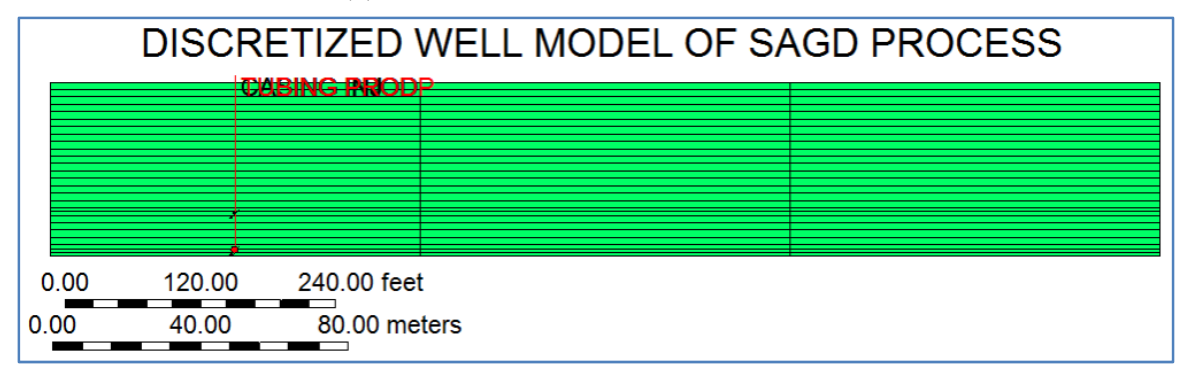

(b) J-K view of the simulation model, injector and producer extend through 3 layers in y-direction

Figure 1. Cross-sectional view of the simulation model showing the position of injection and production wells

\subsection{Discretized Well Model Option}

In order to be able to model the preheating period at the start of the SAGD process, a discretized well model approach was chosen. This option is being provided by CMG reservoir simulator to be able to model the well flow more accurately. The well is then considered as a casing or annulus space with tubing in the middle. Steam is injected through the tubing and flows into the open wellbore at the end of the tubing. The stream flows into the reservoir through perforations and the extra steam is produced to the surface through the annulus space. (CMG-STARS user's guide, 2012) 


\subsection{Rock and Fluid Properties}

In the fluid characterization part of the model, the bitumen was considered as a pseudo component with defined properties. It was the only component in the oil phase with no solution gas. The PVT properties of the Athabasca bitumen such as density, molecular weight and viscosity behavior versus temperature, measured in the laboratory, were used in the fluid characterization model (Ashrafi et al., 2011). Figure 2 shows the viscosity variation by temperature used in this simulation study.

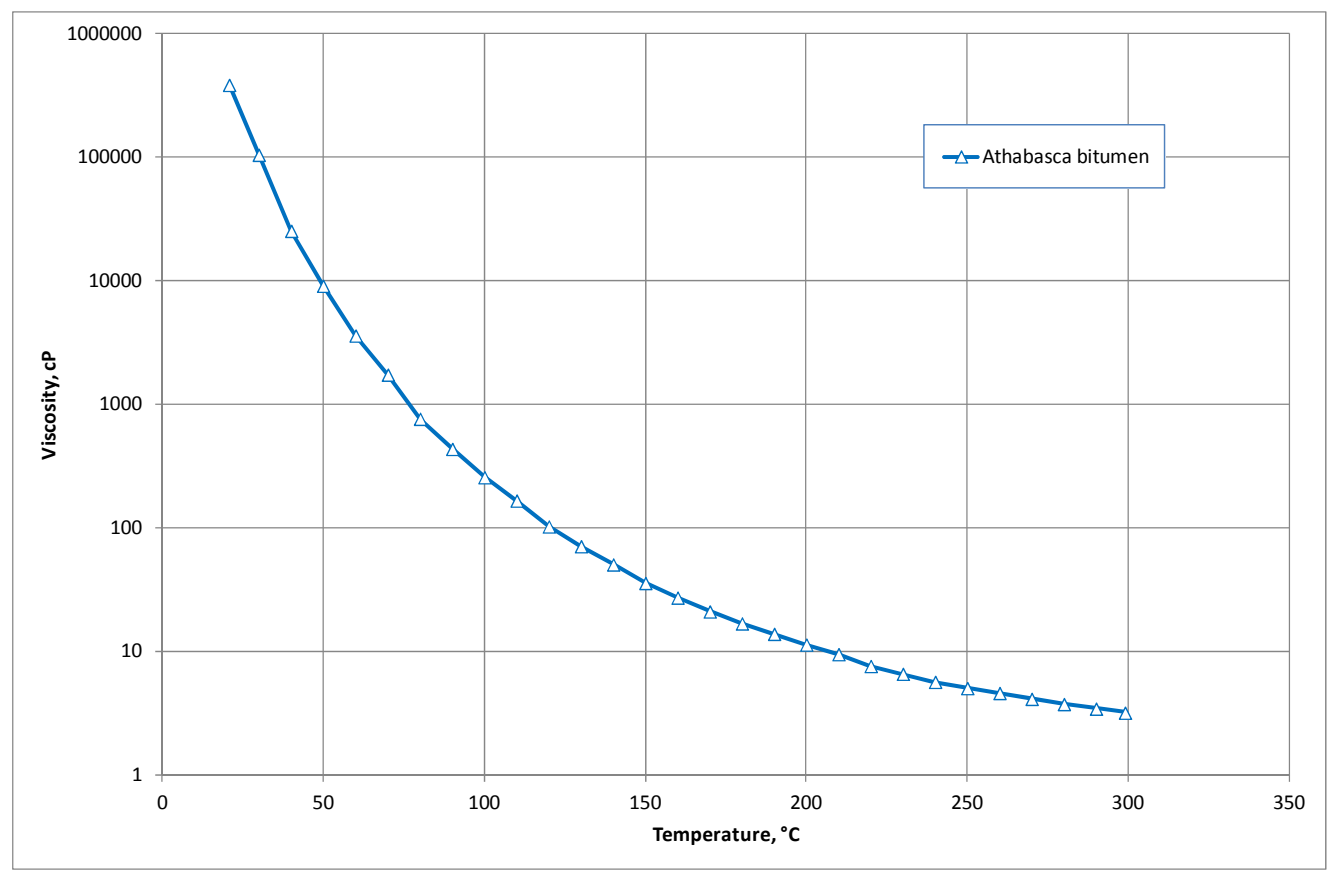

Figure 2. Viscosity of Athabasca bitumen versus temperature (Ashrafi et al., 2011)

For the viscosities of the solvents used in ES-SAGD process simulations, the internal liquid viscosity correlation for some selected normal alkanes presented in STARS manual was used. This equation is as follows (CMG-STARS user's guide, 2012):

$$
V I S C=A V I S C \times \exp (B V I S C / T)
$$

Where values of the coefficients AVISC and BVISC are given for selected components in STARS manual, VISC is viscosity and $T$ is absolute temperature.

The advantageous effect of adding solvents to the steam in any solvent co-injection process is the viscosity reduction of bitumen as a result of solubility. Solubility of the solvents in bitumen is reflected in K-values of the solvents. K-values are the ratios of the mole fraction of each solvent in vapor phase to that in liquid phase at thermodynamic equilibrium condition. K-values are therefore temperature, pressure and concentration dependant In this study the K-values of the solvents versus temperature and pressure were estimated using the following equation provided in STARS manual (CMG-STARS user's guide, 2012):

$$
K=(K V 1 / P) \times \exp (K V 4 /(T-K V 5))
$$

Where coefficients $K V 1, K V 4$ and $K V 5$ are component dependant and presented in STARS manual for selected components. $P$ and $T$ are pressure and absolute temperature respectively.

Other fluid and rock properties used in this study are listed in Table 1. 
Table 1. Rock and fluid properties used in the simulation study

\begin{tabular}{|c|c|c|c|}
\hline \multicolumn{2}{|c|}{ Reservoir properties } & \multicolumn{2}{|l|}{ Thermal properties } \\
\hline Horizontal permeability & $7000 \mathrm{mD}$ & Rock heat capacity & $3.52 \times 10^{6} \mathrm{~J} /\left(\mathrm{m}^{3} \cdot{ }^{\circ} \mathrm{C}\right)$ \\
\hline Vertical permeability & $2100 \mathrm{mD}$ & Rock thermal conductivity & $2.164 \times 10^{5} \mathrm{~J} /\left(\mathrm{m}\right.$. day. $\left.{ }^{\circ} \mathrm{C}\right)$ \\
\hline Porosity & 0.33 & Water thermal conductivity & $5.357 \times 10^{4} \mathrm{~J} /\left(\right.$ m.day. $\left.{ }^{\circ} \mathrm{C}\right)$ \\
\hline Reservoir temperature & $11^{\circ} \mathrm{C}$ & Oil thermal conductivity & $1.296 \times 10^{6} \mathrm{~J} /\left(\right.$ m.day. $\left.{ }^{\circ} \mathrm{C}\right)$ \\
\hline Reservoir pressure & $2200 \mathrm{kPa}$ & $\begin{array}{l}\text { Heat capacity of overburden and underlying } \\
\text { layers }\end{array}$ & $2.39 \times 10^{6} \mathrm{~J} /\left(\mathrm{m}^{3} .{ }^{\circ} \mathrm{C}\right)$ \\
\hline Oil saturation & 0.9 & $\begin{array}{l}\text { Thermal conductivity of overburden and } \\
\text { underlying layers }\end{array}$ & $1.69 \times 10^{5} \mathrm{~J} /\left(\right.$ m.day. $\left.{ }^{\circ} \mathrm{C}\right)$ \\
\hline Water saturation & 0.1 & & \\
\hline
\end{tabular}

\subsection{Relative Permeability Data}

Previous laboratory core flooding experiments by the authors have indicated the dependency of the end point relative permeabilities on the temperature (Ashrafi et al., 2012). Therefore it was decided to examine different relative permeability data to check the sensitivity of model to these data. The option to include the temperature dependant end point relative permeability data is provided by CMG-STARS simulator. The basic shape of the relative permeability curves considered was Corey type (Corey, 1954) as follows:

$$
\begin{aligned}
& k_{r w}=k_{r w}^{0}\left(S_{w}^{*}\right)^{N_{w}} \\
& k_{r o}=k_{r o}^{0}\left(1-S_{w}^{*}\right)^{N_{o}}
\end{aligned}
$$

Where, $S_{w}^{*}$ is normalized water saturation:

$$
S_{w}^{*}=\frac{S_{w}-S_{w i}}{1-S_{w i}-S_{o r}}
$$

The same type of equation form applies to the liquid-gas relative permeability curves. All the Corey type exponents $(N)$ were considered to be equal to 1.5 arbitrarily. One set of relative permeability data is referred to as HSor (High residual oil saturation) in which the residual oil saturation is considered to be 0.38 . This set of data was used in simulations as a basic case for comparison. In another set of simulation runs, the same relative permeability data as HSor was used together with the temperature dependant end points option. It was assumed therefore that the initial water saturation is rising and the residual oil saturation is decreasing as the temperature increases. A third relative permeability data set is considered with a lower residual oil saturation of 0.25 . This set is referred to as LSor (Low residual oil saturation). This was used as a control check to see the difference in having a fixed $\mathrm{S}_{\text {or }}$ or a temperature dependent $\mathrm{S}_{\mathrm{or}}$. Figure 3 shows both HSor and LSor relative permeability data sets.

The case of temperature dependant relative permeability data uses the same data as HSor together with the temperature dependant values listed in Table 2 . 

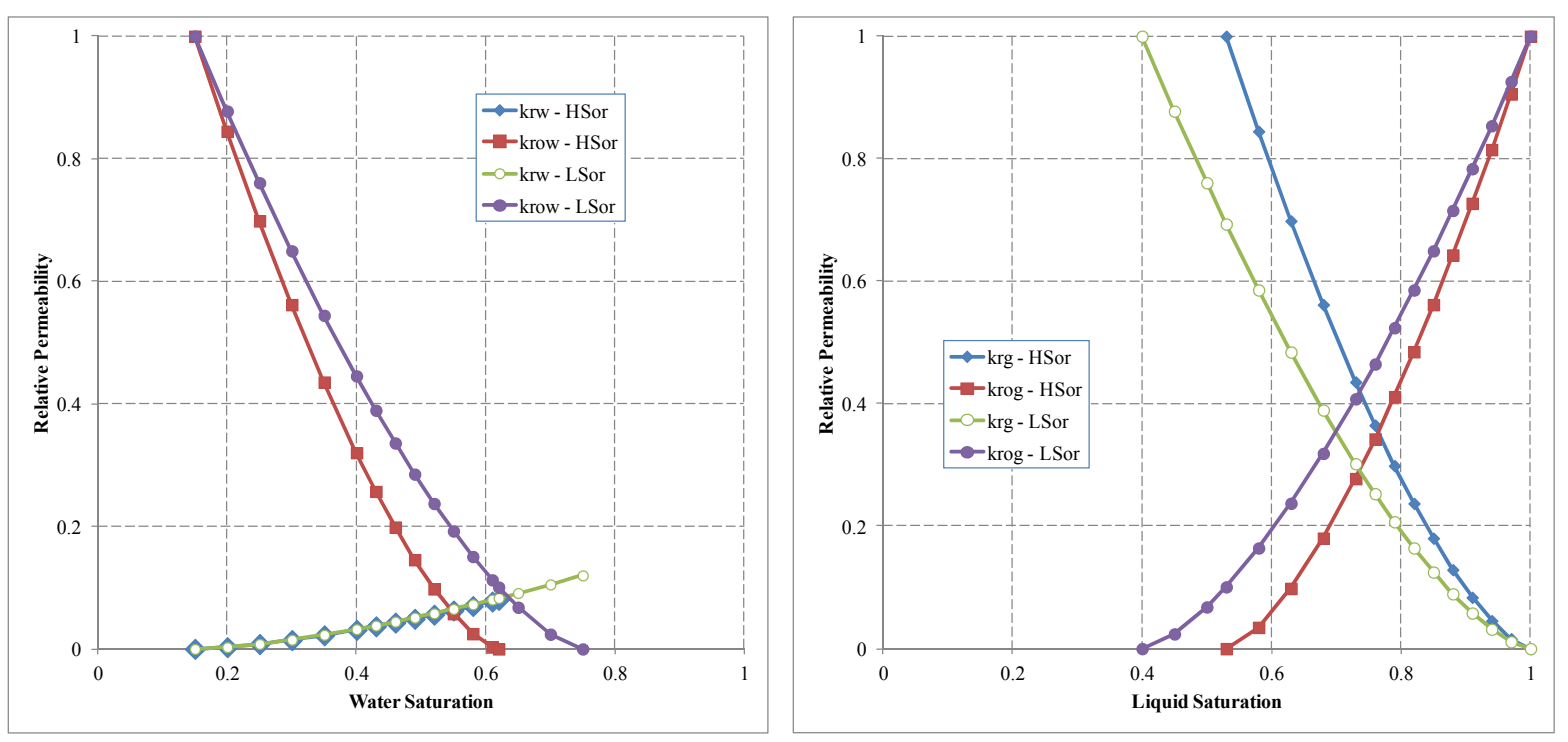

Figure 3. Relative permeability data sets HSor $\left(\right.$ High $\left.\mathrm{S}_{\text {or }}\right)$ and LSor $\left(\right.$ Low $\left.\mathrm{S}_{\text {or }}\right)$

Table 2. Temperature dependant relative permeability data parameters

\begin{tabular}{cccccccc}
\hline Temperature, ${ }^{\circ} \mathrm{C}$ & $\mathrm{S}_{\mathrm{wr}}$ & $\mathrm{S}_{\text {orw }}$ & $\mathrm{S}_{\mathrm{gr}}$ & $\mathrm{S}_{\text {org }}$ & $\mathrm{k}_{\text {rwiro }}$ & $\mathrm{k}_{\text {rocw }}$ & $\mathrm{k}_{\text {rgcw }}$ \\
\hline 15 & 0.15 & 0.40 & 0 & 0.38 & 0.08 & 1 & 1 \\
105 & 0.20 & 0.34 & 0 & 0.32 & 0.10 & 1 & 1 \\
195 & 0.25 & 0.28 & 0 & 0.25 & 0.12 & 1 & 1 \\
\hline
\end{tabular}

Where:

$\mathrm{S}_{\mathrm{wr}}$ Irreducible water saturation

$\mathrm{S}_{\text {orw }}$ Residual oil saturation for water injection

$\mathrm{S}_{\mathrm{gr}} \quad$ Critical gas saturation

$\mathrm{S}_{\text {org }}$ Residual oil saturation for gas injection

$\mathrm{k}_{\mathrm{rwiro}}$ Relative permeability to water at irreducible oil saturation for water injection

$\mathrm{k}_{\text {rocw }}$ Relative permeability to oil at connate water and zero gas saturation

$\mathrm{k}_{\mathrm{rgcw}}$ Relative permeability to gas at connate liquid.

\subsection{Operation Scenario}

This simulation study was conducted to represent a field scale SAGD process. It consisted of several injection phases. The discretized injector and producer wells defined are used to circulate steam of temperature $325^{\circ} \mathrm{C}$ and 0.8 quality in a 3 month period. This pre-heating period is simulated to represent the circulation phase in an actual SAGD project. The goal is to warm up the space between the well pairs and establish an initial communication between the wells. After the pre-heating period, the high pressure SAGD phase starts when the temperature of steam is $325^{\circ} \mathrm{C}$ and the quality is 0.9 . The steam was injected with a rate of $100 \mathrm{~m}^{3} /$ day for a 2 month period, and then with a reduced injection rate of $50 \mathrm{~m}^{3} /$ day for 1.5 month as a depressurization phase. The normal SAGD phase was then initiated at 6.5 month from the start of the whole process until the end. The whole simulation run was about 9-10 years depending on the oil rate at final stages, as the process was set to stop if the oil rate dropped to $2 \mathrm{~m}^{3} /$ day. The well constraints in SAGD phase was a maximum pressure of $5500 \mathrm{kPa}$ and maximum injection rate of $250 \mathrm{~m}^{3} /$ day for the injector and a minimum bottom hole pressure of $5200 \mathrm{kPa}$ for the producer. The injected steam had a temperature of $270^{\circ} \mathrm{C}$ and a quality of 0.9 . There was a maximum liquid rate of $150 \mathrm{~m}^{3} /$ day for the producer at the first year of SAGD process, which was then raised to $250 \mathrm{~m}^{3} / \mathrm{day}$. The maximum steam production rate was also considered for the producer to prevent the production of live steam. During the ES-SAGD runs, the process was turned to solvent co-injection after about one year from the 
beginning of the SAGD phase. This was set at the same time as the jump in the maximum production rate for the producer well. The ES-SAGD phase lasted for 5.25 years, and then turned to SAGD when the oil production rate was dropping in order to produce back as much of the solvent as possible.

\section{Numerical Simulation Results and Discussions}

Three SAGD cases were simulated using three sets of relative permeabilities described earlier. These base cases were considered to figure out the behavior of the model mainly with respect to variable end points. The case HSor has a higher residual oil saturation $\left(\mathrm{S}_{\text {or }}=0.38\right)$ than LSor $\left(\mathrm{S}_{\text {or }}=0.25\right)$. These two permeability sets were fixed, however, the third set was a temperature dependant set. It was basically the same as HSor at reference temperature and gradually shifting towards LSor at higher temperatures especially in terms of $\mathrm{S}_{\text {or }}$. The recovery factors are compared in Figure 4. As the figure shows the ultimate oil recovered in both LSor and Temperature dependant cases are about the same, however, the rate of recovery is higher when using temperature dependant relative permeability data. The oil production rates for these three cases are also depicted on Figure 5 for comparison.

In lack of actual field production data, it is really hard to judge which relative permeability set is matching the reservoir behavior best, but this clearly shows the sensitivity of the SAGD production data to this important piece of data, namely relative permeabilities. Previous work by the authors (Ashrafi et al., 2012) has shown the dependency of end points on the temperature, and it seems crucial to consider this fact as a matching criterion when one is trying to match SAGD field data with a numerical reservoir simulator.

The two relative permeability sets of HSor and temperature dependant (TD) were chosen for the rest of the runs to examine the effect of solvent co-injection in the model. Three normal alkanes were added to the model as solvents to help reduce the viscosity of Athabasca bitumen. Normal pentane, normal hexane and normal heptane were tested as solvents in the ES-SAGD process.

Different simulation runs indicated that the best scenario was to start the injection of solvent at about 1.75 years from the start of the simulations (1 year after the start of normal SAGD phase), when the process is mature, and the steam chamber almost hits the top of the formation. Starting the injection of solvent before this time was not increasing the recovery while spending valuable solvent. The injection of solvent continued for 5.25 years and was stopped at the end of the $7^{\text {th }}$ year. Injecting solvent with steam beyond this time was also not beneficial as there was no more increased recovery. Starting from $7^{\text {th }}$ year until the end of the simulation runs was a normal SAGD operation to help produce as much of the oil and solvent in place as possible.

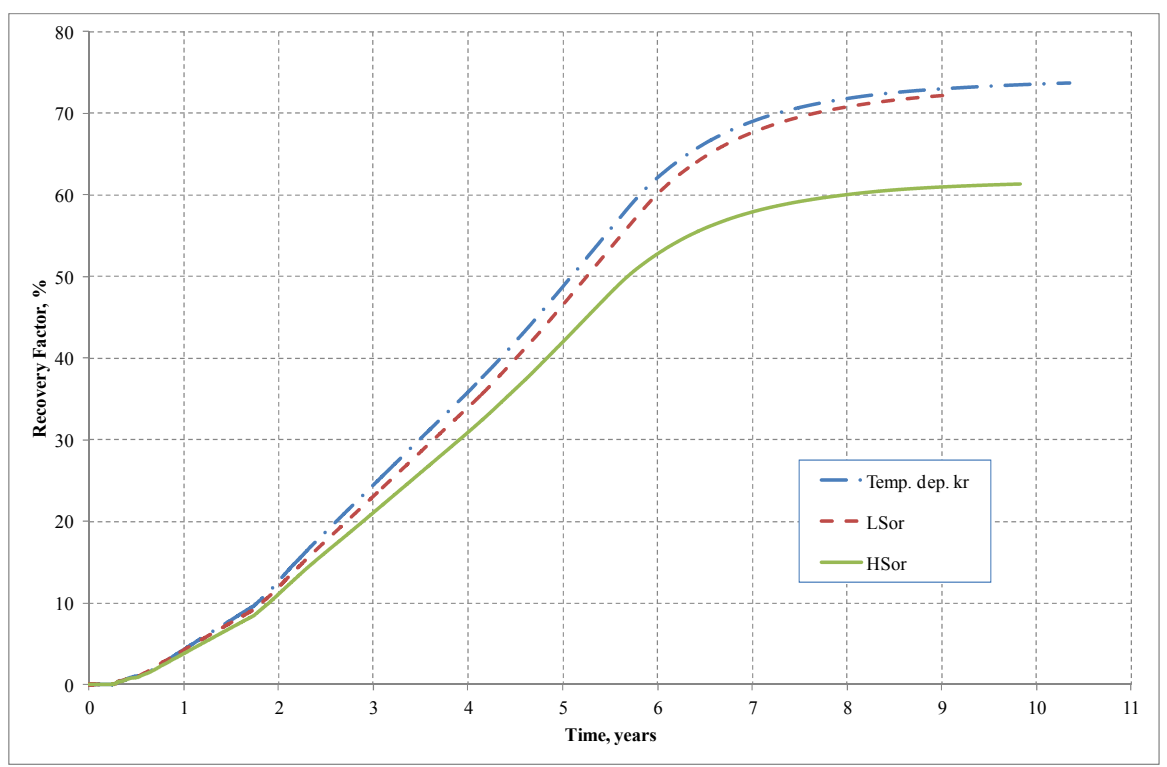

Figure 4. Recovery factors for the three different relative permeability sets: Temperature dependant, Low $\mathrm{S}_{\text {or }}$ and High $\mathrm{S}_{\text {or }}$ 


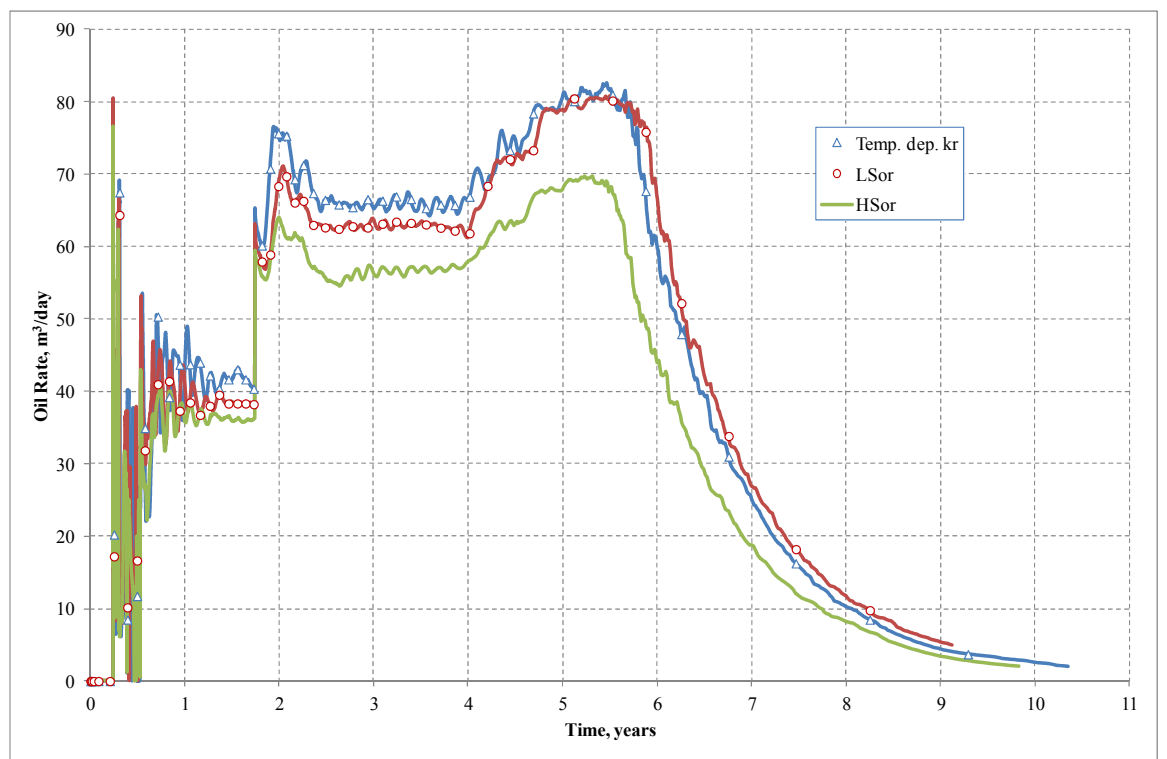

Figure 5. Oil production rate for the three relative permeability sets

Figure 6 compares the recovery factors of SAGD and ES-SAGD processes for the temperature dependant relative permeability (TD) case. The amount of solvents co-injected is $1 \%$ molar based in this case.

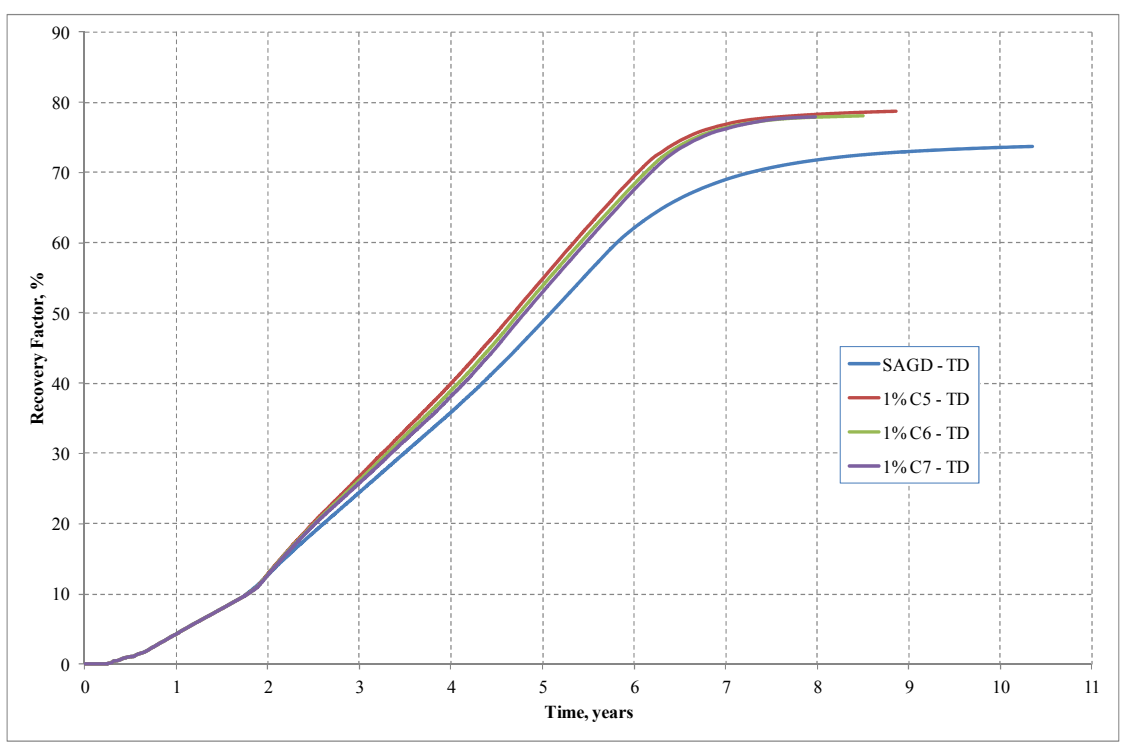

Figure 6. Oil recovery factor for the TD (Temperature Dependant $\mathrm{k}_{\mathrm{r}}$ ) case - Co-injecting $1 \%$ solvent

As seen on the figure there is a minor difference between $\mathrm{C}_{5}, \mathrm{C}_{6}$ and $\mathrm{C}_{7}$ in terms of increasing the oil recovery factor. In all the three solvent cases the recovery is higher than SAGD by about a 5\% increase.

The co-injection of solvent together with steam seems to be quite efficient in terms of solvent recovery. Figure 7 shows the amount of solvent in place expressed in standard cubic meters. Knowing that total amount of injected solvents are $20003 \mathrm{Sm}^{3}, 22922 \mathrm{Sm}^{3}$ and $25849 \mathrm{Sm}^{3}$ of $\mathrm{C}_{5}, \mathrm{C}_{6}$ and $\mathrm{C}_{7}$ respectively, the solvent recovery is $98.3 \%$ for both pentane and hexane co-injection and $97.2 \%$ for heptane co-injection case. 


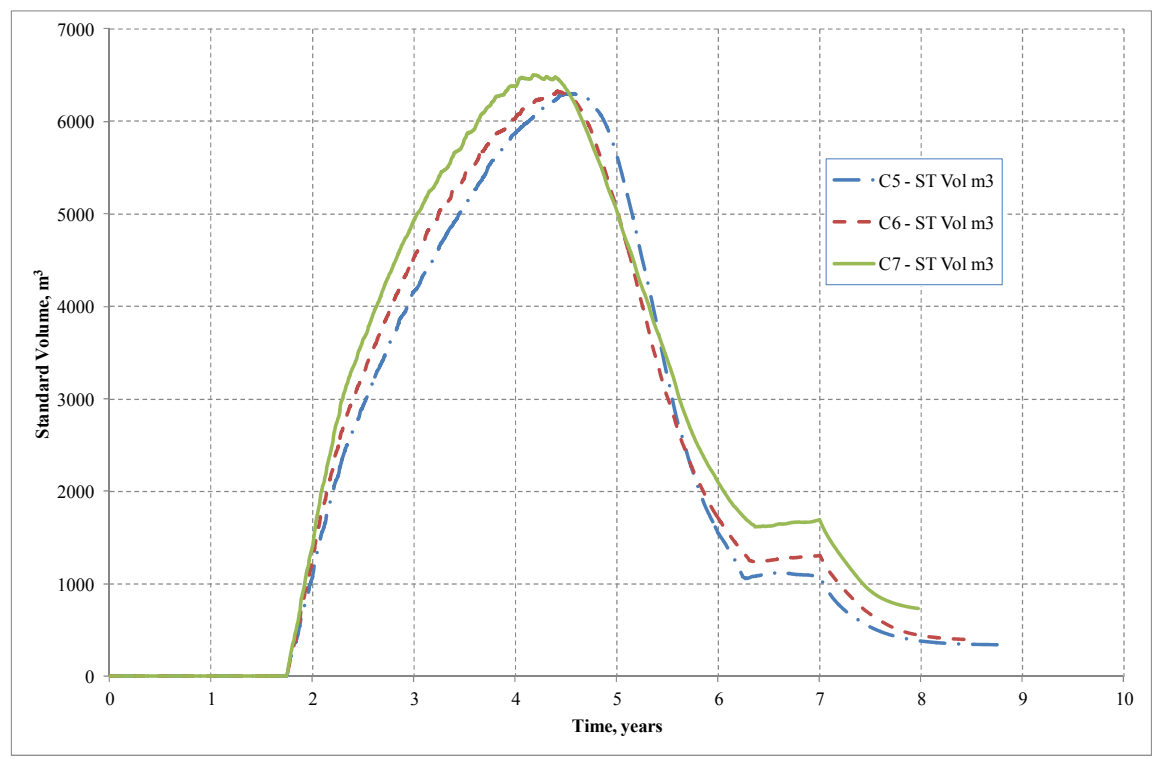

Figure 7. Solvent in place in terms of standard volume for $1 \%$ solvent ES-SAGD - TD case

The increase in oil recovery factor by co-injecting solvents seems to be more pronounced in the case of HSor relative permeability set. The recovery factors are revealed in Figure 8. Again the three solvents are acting about the same, pushing up the ultimate recovery by about $10.5-11 \%$ compared to pure SAGD. The oil rate comparison between SAGD and ES-SAGD is shown on part b of Figure 8. The oil rate for the co-injection of pentane is only compared against base SAGD case, as it was almost the same for the other solvents. The period of time during which solvent is co-injected into the reservoir together with steam is quite visible on this figure. The oil rate during this period is higher. At the end of the $7^{\text {th }}$ year, when the injection of solvent is stopped and the process is changed back to normal SAGD, the oil rate drops below the base SAGD case. The positive effect of solvent in reducing the viscosity by dissolving in bitumen is the cause of higher oil rates. The solvent co-injection (SCI) process is improving the economy of the oil production operation by reducing the steam oil ratio (SOR). SOR is defined as the ratio of injected steam in terms of cold water equivalents (CWE) to the amount of oil produced. SOR is considered as an economical parameter when comparing different operations to recover viscous oils. As depicted on Figure 8c, the cumulative SOR is reduced when solvent is added to steam. The energy lost to over and under-burden layers during the operations are compared on part $d$ of Figure 8. There seems not to be a big difference between SAGD and SCI processes in terms of energy loss.

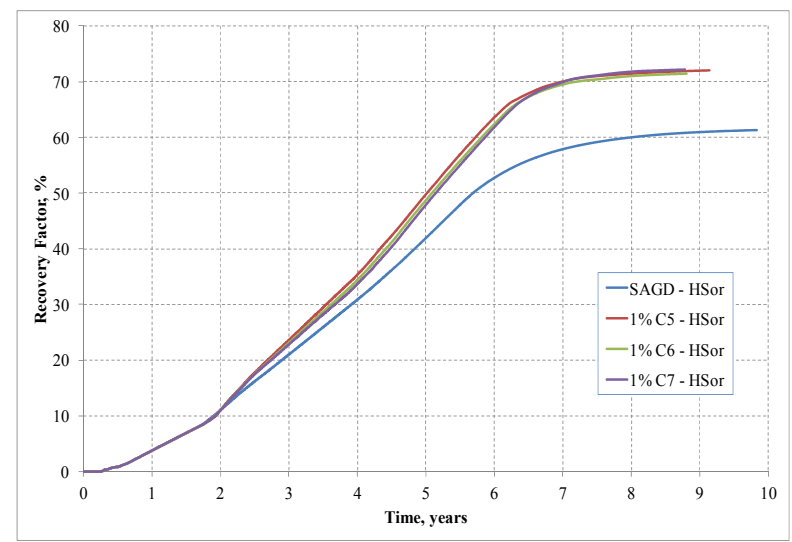

(a) Oil recovery factor

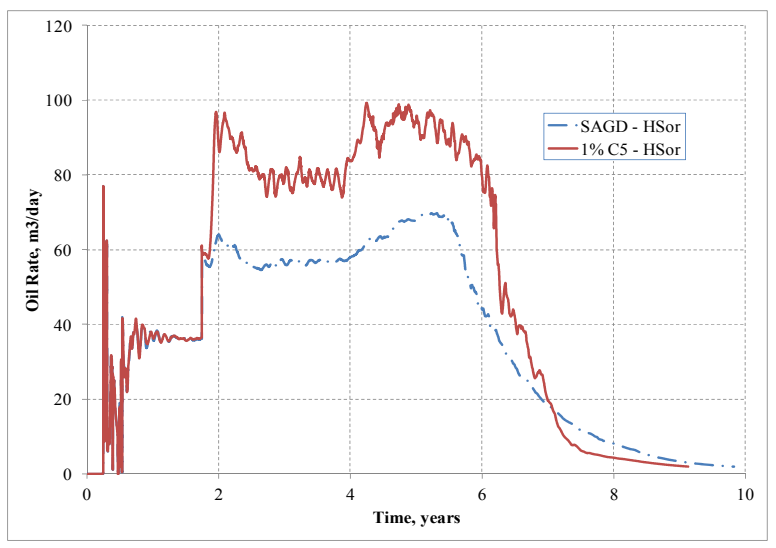

(b) Oil rate 


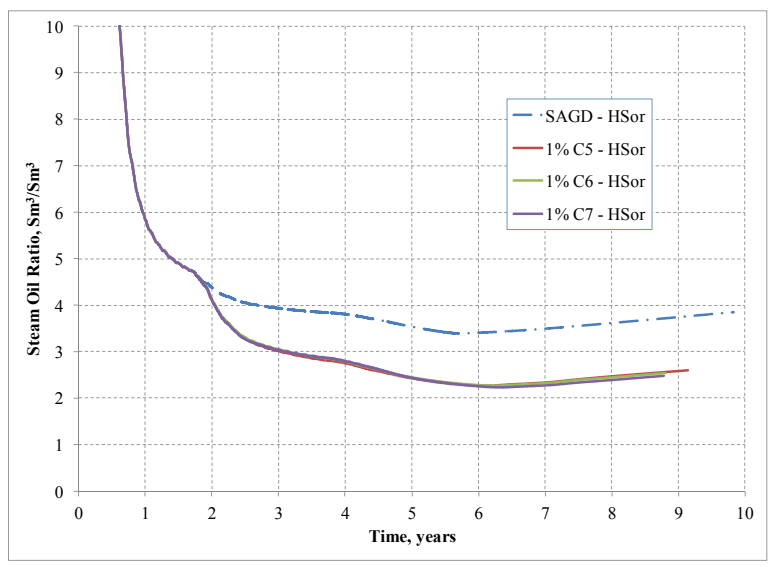

(c) Cumulative steam oil ratio

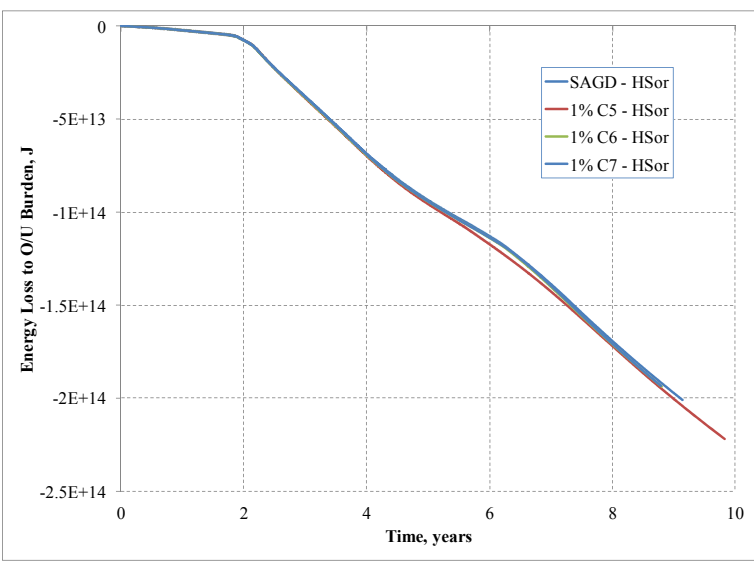

(d) Energy loss to over/under-burden

Figure 8. Comparison between SAGD and ES-SAGD for the HSor (High $\mathrm{S}_{\mathrm{or}}$ ) case - Co-injecting 1\% solvent

Another set of simulation runs were accomplished to figure out how much more oil can be recovered by doubling the amount of solvent used. As such $2 \%$ of solvent was added to the steam on a molar basis. The rise in recovery factors was considerable compared to $1 \%$ solvent case. The recovery factors are shown in Figure $9 \mathrm{a}$ for temperature dependant relative permeabilities (TD) case. The recovery factor rises to about $86.6 \%$ for $2 \%$ pentane co-injection and $89.1 \%$ and $89.6 \%$ for $2 \%$ co-injection of hexane and heptane respectively. The recovery factor improvements are even more dramatic for the HSor $\left(\right.$ High $\mathrm{S}_{\mathrm{or}}$ ) relative permeability case, which is not temperature dependant. They show an increase of about $22.8-25.8 \%$ for the three tested solvents compared to the base SAGD run (Figure 9b). On parts $\mathrm{c}$ and d of Figure 9 production oil rates are demonstrated. The comparison is depicted only for the case of heptane co-injection with steam. The impact of injecting 1 or $2 \%$ of solvent on a molar basis is clearly visible on boosting the oil rates up during the co-injection phase of the operation as compared to the pure SAGD process. Injecting only 1 or $2 \%$ of normal alkanes as solvent together with the steam not only improves the final amount of oil recovered, it also makes the whole operation less polluting. As can be seen on parts e and f of Figure 9, the amount of cumulative steam oil ratio drops as a result of both higher oil production and lower steam injection. Generating and injecting lower amount of steam is beneficial to the environment as well as the economy of the operation, as steam production requires burning of valuable hydrocarbons. This, however, raises some questions about the value of the injected solvents and its effect on the cost of operations. It is beyond the scope of this study to consider the costs of operation, however, as it will be shown later, most of the injected solvents are recoverable during the SCI process.

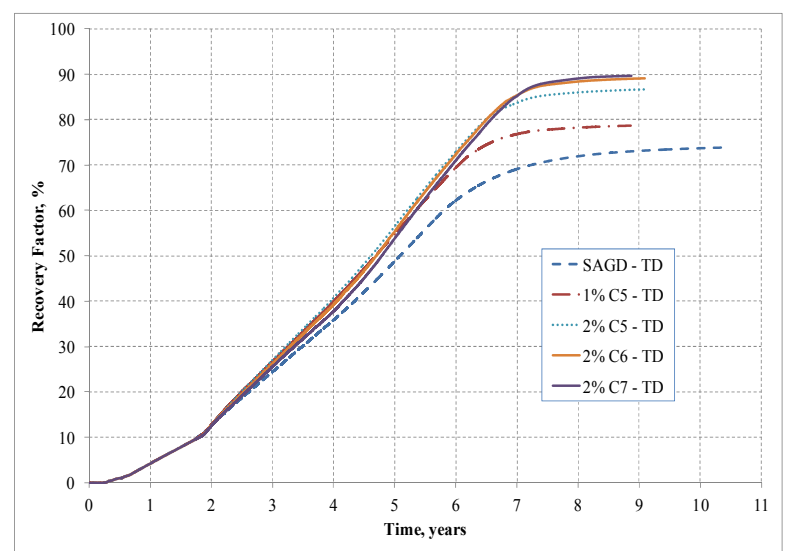

(a) Recovery factor - TD rel. perm. data set

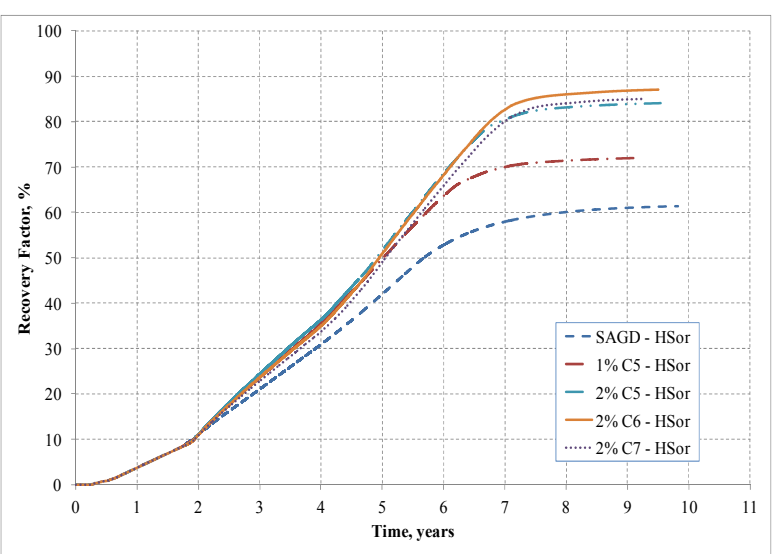

(b) Recovery factor - Hsor rel. perm. data set 


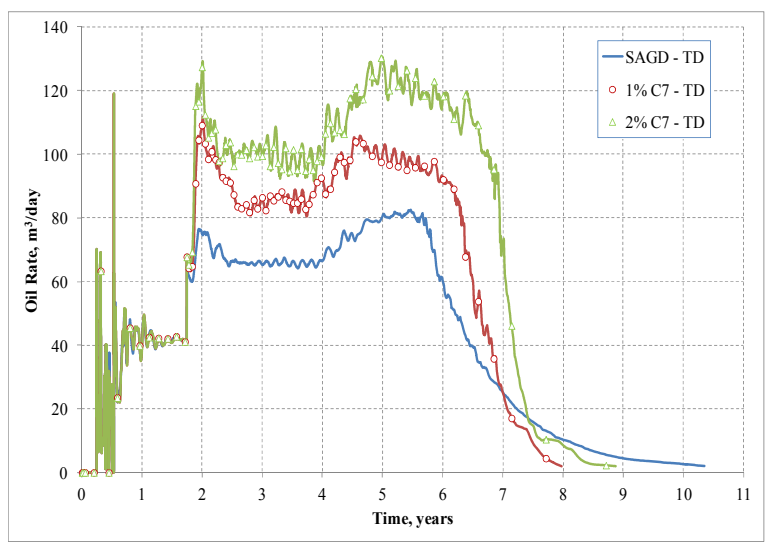

(c) Oil production rate - TD rel. perm. data set

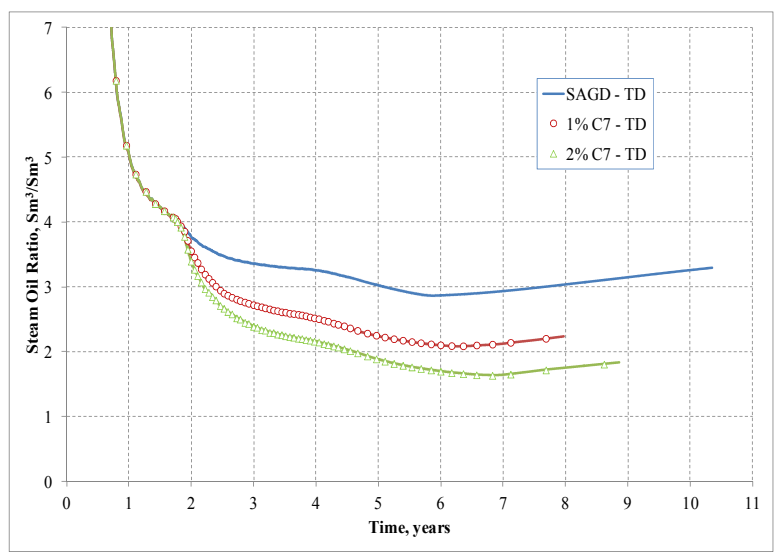

(e) Cumulative steam oil ratio - TD rel. perm. data set

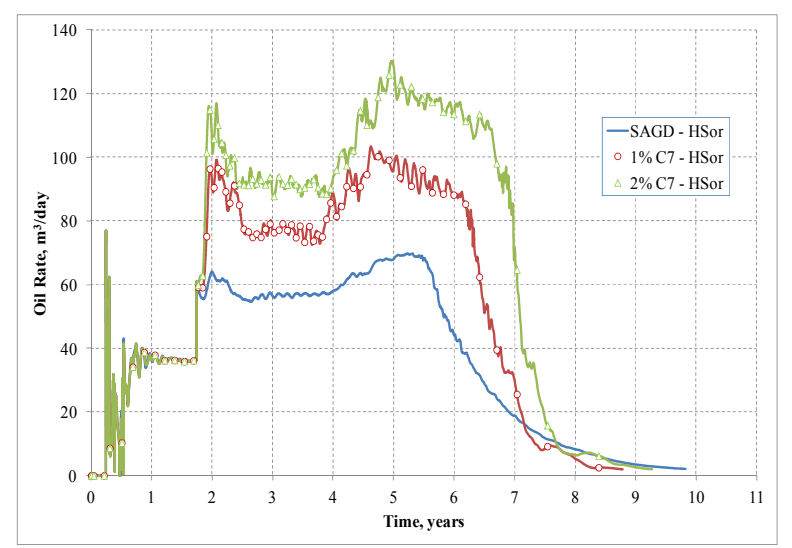

(d) Oil production rate - Hsor rel. perm. data set

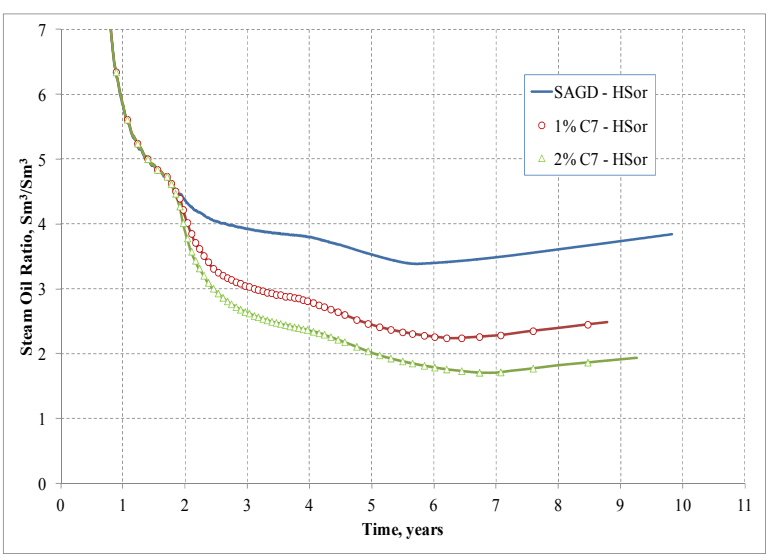

(f) Cumulative steam oil ratio - Hsor rel. perm. data

Figure 9. Comparison between SAGD and ES-SAGD with two different solvent loadings of $1 \%$ and $2 \%$ molar based for the two different permeability data - TD (Temperature Dependant $\mathrm{k}_{\mathrm{r}}$ ) and HSor (High $\mathrm{S}_{\mathrm{or}}$ )

Figure 10 compares the cumulative volumes of solvent injected and produced for some of the simulation runs. When the injection of solvent begins, it takes some time for the solvent to accumulate inside the reservoir and diffuse into bitumen. That causes the production of solvents to occur late as seen on Figure 10 plots. However, almost the whole amount of solvent that is injected in each run is produced at the final stages.

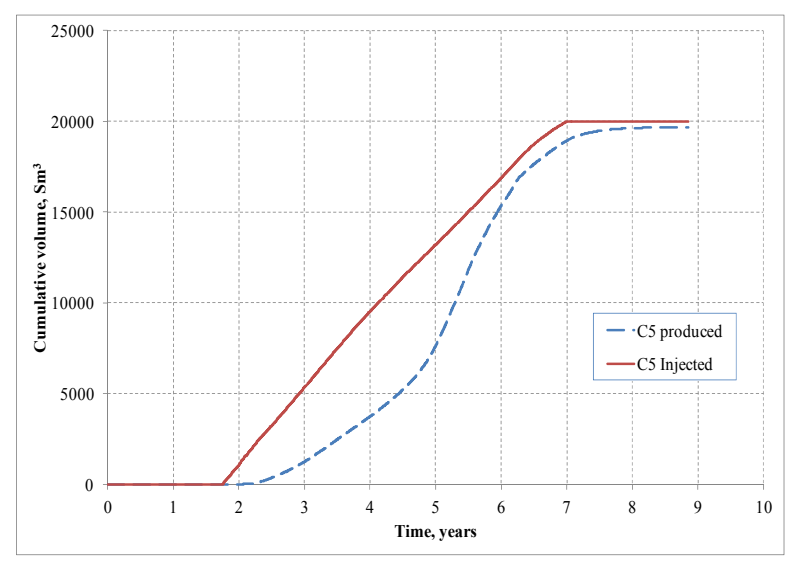

(a) 1\% C5 Co-injection - TD rel. perm. data set

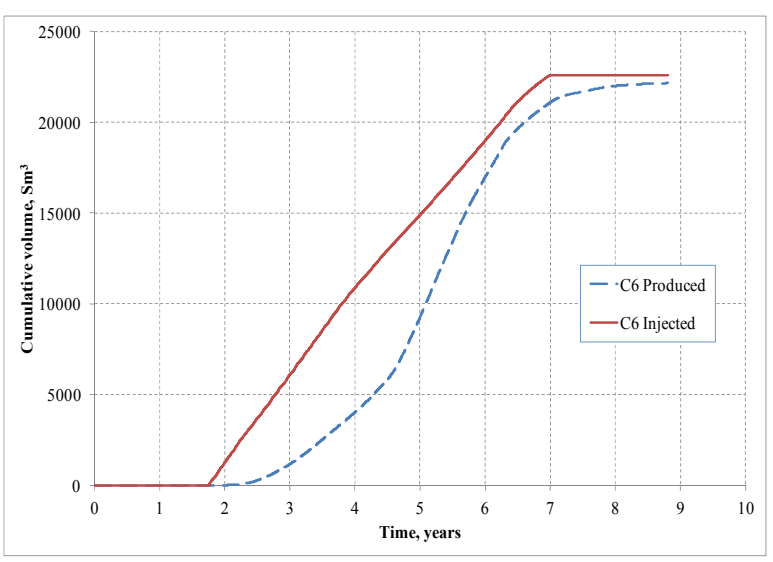

(b) $1 \%$ C6 Co-injection - Hsor rel. perm. data set 


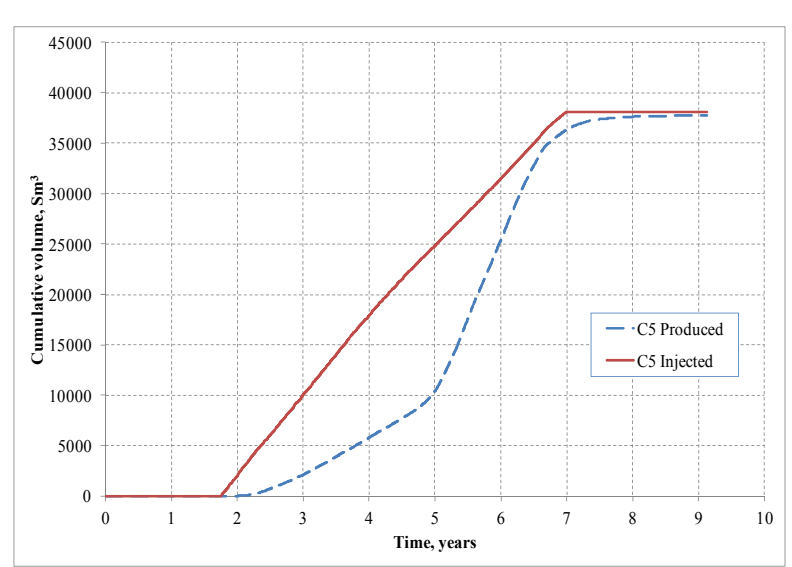

(c) 2\% C5 Co-injection - TD rel. perm. data set

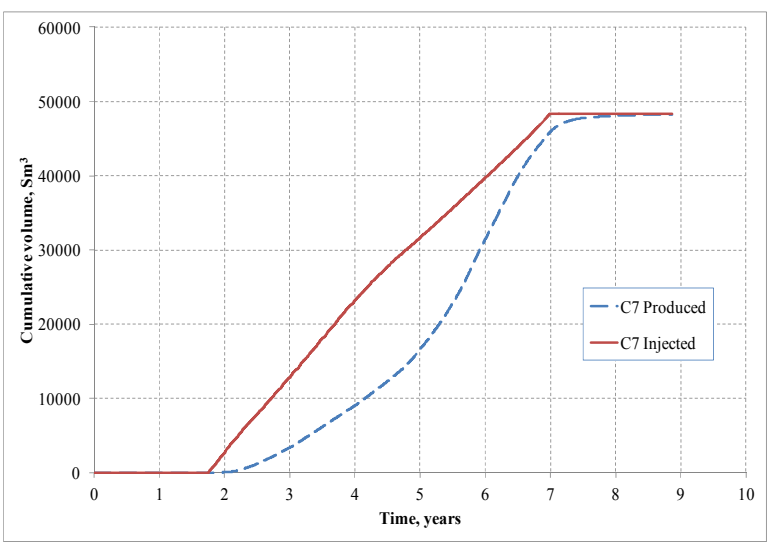

(e) 2\% C7 Co-injection - TD rel. perm. data set

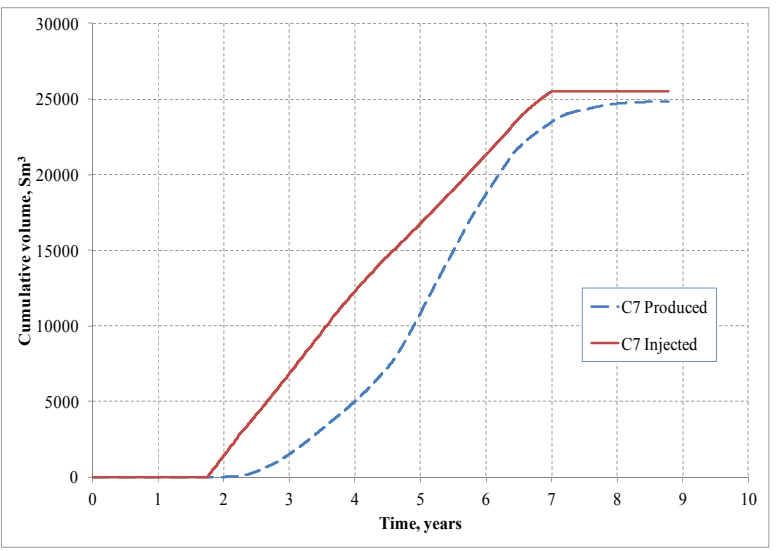

(d) 1\% C7 Co-injection - Hsor rel. perm. data set

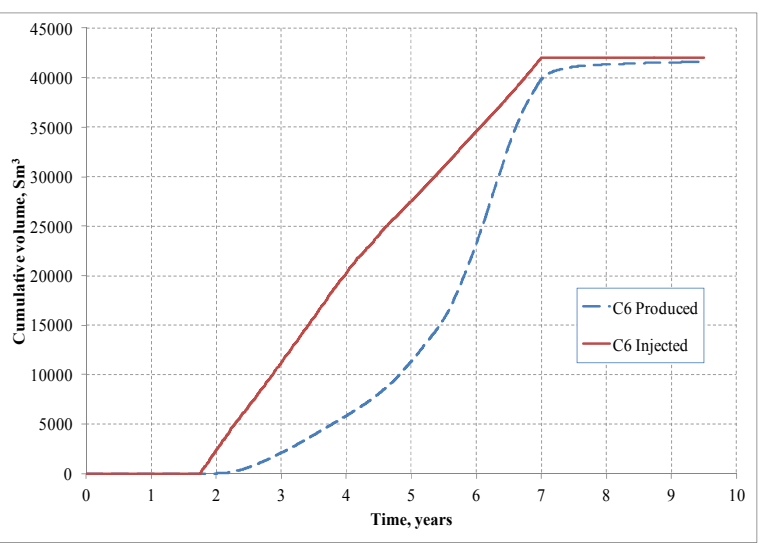

(f) 2\% C6 Co-injection - Hsor rel. perm. data set

Figure 10. Cumulative volume of solvent injected and produced expressed in standard condition volume

The plots on Figure 11, showing the solvent recovery, demonstrate the ratio of solvent production to injection. At the end of the operation about $97-100 \%$ of the injected solvent was recovered in all the cases. The final SAGD phase starting at the end of $7^{\text {th }}$ year in particular was effective to recover any amount of solvent left inside the reservoir. High solvent recovery indicates the privilege of ES-SAGD process compared to normal SAGD operation, because less amount of steam is needed and the extra solvent used is also recovered.

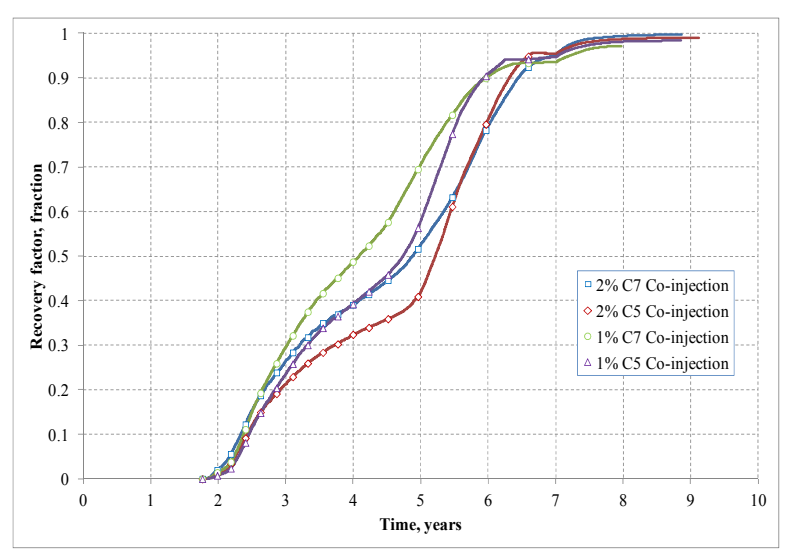

(a) Temperature dependant rel. perm. data set

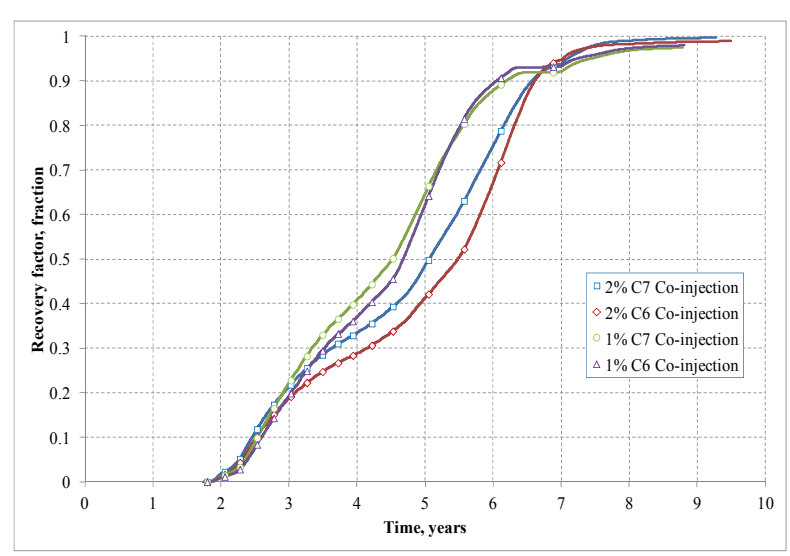

(b) High $\mathrm{S}_{\text {or }}$ rel. perm. data set

Figure 11. Instantaneous solvent recovery factor for the two relative permeability data set simulations 


\section{Conclusions}

Numerical simulation study was conducted to test the effect of relative permeability data on the performance of SAGD and ES-SAGD or SCI (Solvent Co-Injection) processes. Oil production was found to be strongly dependant on the end point relative permeability data. As the results of previous work by authors (Ashrafi et al., 2012) justify the dependency of endpoint data on temperature, it is therefore suggested to use temperature dependant relative permeability data in numerical reservoir simulations. Comparing the use of fixed relative permeability data with shifting data between the two end points shows different outcomes in terms of oil production curve. This must be considered as a matching criterion, when field data are available.

Using different relative permeability data with and without varying end points, the SAGD and ES-SAGD processes were compared. In both cases solvent co-injection showed promising results both in terms of improved recovery factor and reduced steam oil ratio. ES-SAGD process seemed to be superior to SAGD from economical point of view as well, since between 97 to $100 \%$ solvent recovery was achieved in all solvent co-injection runs. Injecting only $2 \%$ on a molar basis of pentane, hexane or heptane as solvent together with the steam, boosted the oil rates and showed increased recovery factors. At the end of the operation, normal SAGD was conducted to produce back any amount of solvent trapped inside the reservoir.

\section{Acknowledgements}

The authors would like to acknowledge Statoil ASA's financial support during the course of our research. We also thank Computer Modeling Group for providing us the license to CMG reservoir simulator.

\section{References}

Albahlani, A. M., \& Babadagli, T. (2008). A critical review of the status of SAGD: where are we and what is next? Paper SPE 113283 presented at the SPE Western Regional and Pacific Section AAPG joint meeting held in Bakersfield, California, USA, 31 March-2 April. http://dx.doi.org/10.2118/113283-MS

Ashrafi, M., Soraki, Y., \& Torsaeter, O. (2012). Effect of Temperature on Athabasca Type Heavy Oil - Water Relative Permeability Curves in Glass Bead Packs. Energy and Environment Research, 2(2), 113-126. http://dx.doi.org/10.5539/eer.v2n2p113

Ashrafi, M., Souraki, Y., Karimaie, H., Torsaeter, O., \& Bjorkvik B. J. A. (2011). Experimental PVT Property Analyses for Athabasca Bitumen. Paper CSUG/SPE 147064 presented at the Canadian Unconventional Resources Conference held in Calgary, Alberta, Canada, 15-17 November. http://dx.doi.org/10.2118/147064-MS

Butler, R. M., McNab, G. S., \& Lo, N. Y. (1981). Theoretical Studies on the Gravity Drainage of Heavy Oil During In-Situ Steam Heating. The Canadian J. Chem. Engineering, 59, 455-460, Aug. 1981. http://dx.doi.org/10.1002/cjce.5450590407

Chow, L. (1993). Numerical Simulation of Heavy Oil Recovery by the Steam-Assisted Gravity Drainage Process. M. Eng. Thesis, University of Calgary.

Chung, K. H. (1988). Heavy Oil Recovery by the Steam-Assisted Gravity Drainage Process. Ph.D. Thesis, University of Calgary.

CMG-STARS User's Guide. (2012). Computer Modeling Group Ltd.

Corey, A. T. (1954). The Interrelation between Gas and Oil Relative Permeabilities. Producers Monthly, 19(1), 38-41. http://www.discovery-group.com/pdfs/Corey_1954.pdf

Deng, X., Huang, H., Zhao, L., Law, D. H. S., \& Nasr, T. N. (2010). Simulating the ES-SAGD process with solvent mixture in Athabasca reservoirs. Journal of Canadian Petroleum Technology, 49(1), 38-46. http://dx.doi.org/10.2118/132488-PA

Kamath V. A., Sinha, S., \& Hatzignatiou, D. G. (1993). Simulation Study of Steam-Assisted Gravity Drainage Process in Ugnu Tar Sand Reservoir. paper SPE 26075 presented at the Western Regional Meeting, Anchorage, Alaska. http://dx.doi.org/10.2118/26075-MS

Kisman, K. E., \& Yeung, K. C. (1995). Numerical Study of SAGD Process in the Burnt Lake Oil Sands Lease. paper SPE 30276 presented at the International Heavy oil Symposium, Calgary, Alberta, Canada. http://dx.doi.org/10.2118/30276-MS

Nasr, T. N., \& Isaac, E. E. (2001). Process for Enhancing Hydrocarbon Mobility Using a Steam Additive. United States Patent No. 6,230,814, 15 May 2001.

Yazdani, A., Alvestad, J., Kjonsvik, D., Gilje, E., \& Kowaleski, E. (2012). A parametric simulation study for solvent co-injection process in bitumen deposits. Journal of Canadian Petroleum Technology, 51(4), 244-255. http://dx.doi.org/10.2118/148804-PA 